\title{
Feminismo como propuesta didáctica para la clase de E/LE: imágenes y música
}

\author{
FLORENCIA BATTAGLIERO BOCCO \\ Universitat de València \\ flobatt@alumni.uv.es \\ José VicEnTE FontANA OLTRA \\ Universitat de València \\ jofonol@alumni.uv.es \\ Marta NAVARro Morales \\ Universitat de València \\ marnamo2@alumni.uv.es
}

Resumen: El objetivo de esta propuesta es tratar la temática del feminismo a través de la interculturalidad mediante el uso de actividades que permitan desarrollar las Inteligencias Múltiples -ejercitando las cuatro destrezas y el contenido gramatical que indica el Plan Curricular del Instituto Cervantes ${ }^{1}$ - en un grupo de nivel $\mathrm{B}^{2}$. Se emplearán fragmentos de canciones que los aprendientes (sobre todo, el alumnado juvenil) pueden encontrar durante su inmersión en la cultura hispana. Posteriormente, se abordará el feminismo mediante infografías e imágenes. Por último, se utilizará la aplicación de mensajería WhatsApp como medio de debate dentro y fuera del aula. Se fomentará el pensamiento crítico empoderando a la mujer, se reflexionará sobre el discurso androcéntrico existente en la mayoría de las culturas y se aplacará la falsa idea de feminismo como batalla de sexos.

Palabras claves: E/LE, feminismo, machismo, Inteligencias Múltiples, Interculturalidad

\section{Feminism as didactic proposal for the Spanish classes: images and music}

Abstract: The purpose of the following essay is to work on feminism through interculturalism using activities allowing the development of Multiple Intelligences practising the four skills and some grammatical content as pointed out by the "Plan Curricular del Instituto Cervantes" - in a B2-level group. First, the instructor will use extracts from songs that the learners (especially young pupils) can come across during their Spanish cultural immersion. Then, feminism will be tackled through infographics and images. We will eventually use the messenger application Whatsapp not only as a learning tool, but also as means to debate in and out of the class setting. As a result, critical thinking which empowers women will be encouraged, and male-oriented discourses that exist in most cultures will be considered. Thus, the instructor will weaken the misconception of feminism as a battle of the sexes.

Key words: ELE, feminism, male chauvinism, Multiple Intelligences, interculturalism.

\footnotetext{
${ }^{1}$ En adelante PCIC.

${ }^{2}$ Perteneciente al Marco Común Europeo de Referencia para las Lenguas, en adelante MCERL. 


\section{Estado de la cuestión y justificación de la propuesta}

En muchas ocasiones, el aula de E/LE es una suerte de observatorio de la cambiante realidad de la sociedad. Como fiel reflejo de este fenómeno, suele haber diferentes obstáculos para los estudiantes, como dar una imagen que sea aceptada por la clase, sobre todo cuando se tratan temas polémicos. Este hecho impide que el estudiante disfrute, aprenda y reflexione sobre los aspectos culturales y el contenido de clase.

Como profesores, son muchos los temas que, de manera habitual, abordamos en las clases a través de los manuales. Sin embargo, se detecta la existencia de una serie de realidades que no siempre se reflejan de manera explícita para evitar herir sensibilidades. De esta forma, que se deposita en el profesorado la responsabilidad moral y profesional de tratar temas controvertidos por su sensibilidad ${ }^{3}$ como el machismo, la homosexualidad, la adicción, la enfermedad, la muerte o las drogas, entre otros.

Por ello, el propósito de la presente propuesta consiste en llevar el feminismo al aula a través de una serie de actividades con un tono reflexivo y cotidiano. Por un lado, se intenta desenmascarar tópicos y prejuicios; $y$, por otro, generar en el aula un entorno seguro para evitar que el alumnado se sienta juzgado o presionado a la hora de debatir y expresar sus emociones.

Pese a que la palabra feminismo está a la orden del día y la Real Academia Española (RAE) la recoge de forma clara y concisa ${ }^{4}$, en algunos casos el concepto no se entiende correctamente $\mathrm{o}$, incluso, se estigmatiza o se le atribuyen erróneamente connotaciones negativas $^{5}$. Si tenemos en cuenta que las mujeres representan aproximadamente el $50 \%$ de la población mundial ${ }^{6}$ y que el machismo no es restrictivo de los hombres ni el feminismo de las mujeres, nos encontramos ante un tema que abarca e implica a todas las personas.

\section{Objetivos}

El objetivo de la presente propuesta es tratar el feminismo y la Competencia Intercultural $^{7}$ de manera inclusiva mediante las Inteligencias Múltiples ${ }^{8}$ (en adelante

\footnotetext{
${ }^{3}$ En esta dirección, el Ministerio de Educación, Cultura y Deporte y el Consejo de Europa ponen a disposición del profesorado el módulo de formación «La enseñanza de temas controvertidos» (2015), basado en el artículo «Teaching controversial issues» (2000) de Pat Clarke. También cabe destacar la propuesta didáctica de Jodar Sánchez y Domene Benito (2017) como planteamiento de la homosexualidad en el aula de E/LE.

4 «1. Principio de igualdad de derechos de la mujer y el hombre; y 2. Movimiento que lucha por la realización efectiva en todos los órdenes del feminismo.»

${ }^{5}$ Puede observarse en declaraciones de personalidades influyentes del panorama nacional e internacional como Katy Perry, Taylor Swift, Belén Rueda, Carla Bruni (véase « ¿Feminista, yo? No, gracias» artículo publicado en El País el 05/12/2012), concretamente en políticas de nuestro país a las que no les gusta que les «pongan esta etiqueta» de feminista (Dolors Montserrat, Ministra de Igualdad en una entrevista en la cadena SER, 7/03/2018), o incluso políticos que distorsionan y buscan desprestigiar la lucha feminista fusionando este término con el nazismo, como Rush Limbaugh del Partido Republicano estadounidense, quien en su libro The Way Things Ought to Be (1992) acuñó el despectivo neologismo de «feminazi» referido a las mujeres que decidían sobre su derecho a la maternidad.

${ }^{6}$ Según datos recogidos en el 2017 por el Fondo de Población de las Naciones Unidas (Unfpa.org)

${ }^{7} \mathrm{La}$ enseñanza de la Competencia Intercultural tiene en cuenta «Qué consciencia de la relación existente entre la cultura materna y la cultura objeto de estudio necesitará el alumno para desarrollar una competencia intercultural apropiada» (MCER, 2002:99).
} 
IIMM). Con ello, se pretenden reforzar los aspectos gramaticales del nivel B2 y los pragmáticos como la ironía o el humor.

Como propósito final, se fomenta el pensamiento crítico en el alumnado para reflexionar sobre los prejuicios interiorizados que pasan desapercibidos $\mathrm{y}$, sobre todo, para alejar la falsa idea de feminismo como batalla de sexos.

\section{Duración y perfil del alumnado}

El conjunto de actividades está diseñado para ser trabajado en un grupo máximo de diez estudiantes de un nivel B2 en cursos intensivos de inmersión lingüística en España. Teniendo esto en cuenta, la duración estimada es la siguiente:

\begin{tabular}{|c|c|c|c|}
\hline \multicolumn{2}{|c|}{ PASOS } & TÍTULO & TIPO - DURACIÓN \\
\hline \multirow{2}{*}{ A. Reconocimiento } & 1 & «Di lo primero que piensas» & Semicontrolada - 40” \\
\hline \multirow{2}{*}{ B. Admisión } & 2 & «¿Escuchas lo que cantas?» & Semicontrolada - 30” \\
\hline \multirow{2}{*}{ C. Reflexión } & 3 & «¿Qué hay detrás de las canciones?» & Semicontrolada - 15 \\
\hline \multirow{2}{*}{\begin{tabular}{c}
\multirow{2}{*}{$\begin{array}{c}\text { D. Superación } \mathbf{y} \\
\text { reacción }\end{array}$} \\
\cline { 2 - 5 }
\end{tabular}} & 4 & «Haz tu versión» & Libre - 20 \\
\cline { 2 - 5 } & 6 & «Un poco de humor» & Libre - 15, \\
\hline
\end{tabular}

Imagen 1. Cronograma

Esta propuesta se ha llevado a cabo tanto con jóvenes como con adultos de diferentes nacionalidades. Como consideración previa, cabe destacar la importancia de la confianza entre el docente y el grupo, así como entre el mismo alumnado.

\section{Metodología didáctica, recursos y herramientas}

Se propone una batería de actividades controladas, semicontroladas y libres utilizando las IIMM, y el trabajo individual y en grupo al entender que existen diversos tipos de aprendizaje.

Por esa razón, los recursos que se emplean son diversos: fragmentos musicales, infografías o imágenes con humor satírico. A ellos se accede a través de herramientas como la aplicación de mensajería instantánea WhatsApp, ya que, como nueva tecnología existente, nos obliga a adaptar el aprendizaje a las particularidades de cada entorno de aprendizaje (Gardner 1993b: 222). Se combina, de este modo, el uso de herramientas y material digital o físico: el profesorado cuenta con una guía de apoyo (ANEXO 2) -que se detallará posteriormente- y los estudiantes con una de conversación (ANEXO 1) y tarjetas en las que encontrarán diferentes preguntas para generar debate.

En cuanto a la organización, las cinco actividades propuestas suponen, en su conjunto, una secuencia reflexiva gradual que se divide en cuatro pasos: reconocimiento, admisión, reflexión, superación y reacción.

\footnotetext{
${ }^{8}$ En las clases de E/LE a las que asisten estudiantes de diversos orígenes y edades, se propicia un ambiente de intercambio intercultural desde el que poder abordar un tema de actualidad como el feminismo.
} 


\section{Guía de conversación para el alumnado y guía de apoyo para el docente}

Para trabajar los contenidos gramaticales del nivel se utilizará como referencia a lo largo de las sesiones la guía de conversación (ANEXO 1), en la que aparecen los tres modos -indicativo, subjuntivo e imperativo- con sus correspondientes tiempos verbales; un apartado con el uso de los adjetivos para enfatizar y practicar la prosodia y, sumado todo ello, una batería de recursos como conectores y estructuras ejemplificadas para utilizar en una conversación. Se observan en el ANEXO 1 los ejemplos para expresar deseo con pretérito perfecto de subjuntivo «Espero que no me hayas malinterpretado», o para interrumpir y expresar un acuerdo parcial con presente de subjuntivo «Puede que tengas razón, sin embargo...»».

Teniendo en cuenta la dificultad que supone el uso del subjuntivo y la concordancia temporal para los estudiantes de español de este nivel, a cada tiempo que aparece en la guía le acompaña un símbolo que lo representa y que se utilizará para poder encontrar las combinaciones adecuadas de manera rápida e intuitiva. Por ejemplo: «Me molesta que $+\boldsymbol{\Delta} \bullet »$, donde el triángulo corresponde al presente de subjuntivo y el círculo al pretérito perfecto de subjuntivo 9 . Con ello, se pretende ayudar a los estudiantes con Necesidades Educativas Especiales como la dislexia o para quienes comprenden mejor un concepto abstracto al relacionarlo con un dibujo o imagen ${ }^{10}$. Asimismo, en numerosas ocasiones se da por hecho que el alumnado conoce la terminología y esto no siempre corresponde con la realidad.

A su vez, los docentes dispondrán de una plantilla (ANEXO 2) con preguntas para generar debate y léxico de referencia sobre el tema al que se le ha asignado un número y que servirá al profesorado como indicador de cuándo se recomienda su uso para generar mayor intercambio de opinión y reflexión en el grupo.

\section{Actividad 1 (reconocimiento): «Di lo primero que piensas»}

Para introducir el tema, se realiza un ejercicio de escritura en el que el alumnado deberá escribir las tres primeras palabras (sin importar su categoría gramatical) que le sugieren los términos de hombre, mujer y persona. Se indican de forma gradual las tres palabras y entre cada una se dejan quince segundos para que la clase razone y escriba. Resulta imprescindible respetar el orden para ofrecer una reflexión profunda. Con esta actividad se pretende conocer los introyectos ${ }^{11}$ que mantiene la clase en general y cada alumno en particular sobre el hombre, la mujer y las personas así como el origen de esta perspectiva, ya sea cultural, religiosa, debido a la edad, etc.

\footnotetext{
9 Resulta beneficioso que los estudiantes dispongan de libertad para modificar los símbolos que encuentran en la Guía por aquellos que se ajusten a su experiencia personal e individual para beneficiar su aprendizaje de la lengua.

${ }^{10}$ La profesora e investigadora Reyes Llopis García define la Gramática cognitiva como «un campo de estudio dentro de la Lingüística Cognitiva (LC) que considera que el lenguaje es una habilidad mental que surge de nuestra interacción física y motora con el entorno que nos rodea y por tanto es experiencial, así como representacional, pues está destinado a comunicar los significados que materializan los puntos de vista de los hablantes.» Entrevista del 27/10/2015 disponible en la página web de la editorial Difusión. Véase «Entrevista a Reyes Llopis García, experta en gramática cognitiva y ELE» [Última revisión el $2 / 05 / 2018]$

11 Sobre la relación entre cultura e introyectos en el discurso, véase el trabajo de Anna M. Fernández Poncela (2010: 98). La autora indica que «lo que en algunas corrientes psicológicas denominan comúnmente introyectos e introyectar en la antropología y sociología se llaman estereotipos, que se adquieren durante el proceso de socialización en una cultura determinada.» (2010:101)
} 
La puesta en común de dicha reflexión primero se lleva a cabo por parejas o grupos de tres y se realiza a medida que el profesor descubre una serie de preguntas orientativas en forma de tarjetas (ANEXO 2. Ejemplo: «Desde tu experiencia, ¿puedes explicar por qué has escrito estas palabras? ¿Coincides con tus compañeros?»). Estas permanecerán ocultas para evitar condicionar al alumnado.

A través de la inteligencia intrapersonal e interpersonal, en primer lugar, se busca reflexionar sobre el origen y la causa de sus introyectos y, en segundo lugar, se debate sobre ellos y se contrastan con el resto de la clase desde la interculturalidad.

\subsection{Actividad 2 (admisión): «¿Escuchas lo que cantas?»}

El uso de las canciones en clase de E/LE es bien conocido por crear un ambiente distendido y mejorar la fluidez ${ }^{12} \mathrm{y}$, además, por ser una manera diferente de conocer la cultura de los hispanohablantes. En muchas ocasiones, cuando la canción es pegadiza, resulta inevitable repetir la melodía sin detenerse a pensar sobre el significado de su letra (Jakubowski, Finkel, Stewart y Müllensiefenet 2016). Así pues, en la siguiente actividad se pretende trabajar la visión de la mujer y del hombre reflejada en algunos temas con un contenido machista como son «Si me porto mal», de Dasoul; «Mía» y «Propuesta indecente», de Romeo Santos; y «Picky picky», de Joey Montana (ANEXO $3)$.

\subsubsection{Primera parte}

Se proponen dos alternativas para trabajar la primera parte de la actividad, ya que su elección depende de las características del grupo:

a. Cada estudiante tiene el fragmento de una canción de forma que, mientras cantan y se mueven, deben encontrar al resto de compañeros que tienen la misma letra. Previamente, el profesor debe asegurarse de que conocen las canciones. En caso contrario, pueden escucharla en Youtube o inventar su propio ritmo. Con esta actividad se consigue formar nuevos grupos de trabajo.

b. Por parejas, se les reparte un fragmento de la misma canción con huecos en los que falta una palabra. Por turnos, deben completar la letra indicándose la que falta a través de la mímica. Cada uno tendrá aquellas que necesita el otro estudiante (ANEXO 4). Las palabras resaltadas en negrita indican cuáles son las que no tiene la otra persona. Para practicar de forma conjunta la pronunciación pueden, a la vez, leer en voz alta la canción y al llegar a la palabra resaltada, transmitírsela a su compañero o compañera mediante gestos y mímica.

12 Pueden observarse, a modo de ejemplo, los trabajos de M.L.Coronado y J. García (1990:1-2) Como muestra del uso de la música, el vídeo y el cómic para desbloquear a candidatos que se presentan a pruebas de certificación, se recomienda la lectura de Battagliero Bocco, Fontana Oltra y Navarro Morales (2017). 


\subsubsection{Segunda parte}

Analizan y reflexionan su contenido por parejas mediante las preguntas que se les proporcionan (ANEXO 2) y que van descubriendo de forma progresiva. Posteriormente, se hace una puesta en común en la que comparten con los demás las conclusiones a las que han llegado, dando lugar a un debate común. Finalmente, se muestra el videoclip de las canciones para que, mediante el relato visual del tema, tengan una perspectiva más clara de la representación del hombre -con un papel dominante- y de la mujer -con un rol de subordinación-.

Como se ha podido apreciar, en la primera parte de la actividad se ejercita la pronunciación y la comprensión auditiva a través de la inteligencia musical y la kinestésica. En la segunda parte, se debate de forma grupal y por parejas, y se reflexiona tanto individual como cooperativamente. De este modo, también se trabaja la inteligencia interpersonal e intrapersonal a la hora de expresar sentimientos y emociones en relación con las cuestiones planteadas.

\subsection{Actividad 3 (reflexión): «¿Qué hay detrás de las canciones?»}

$\mathrm{Al}$ abrir la tarjeta donde está la letra de la canción, se encuentra una viñeta de Moderna de Pueblo o Feminista Ilustrada ${ }^{13}$ (ANEXOS 5, 6, 7, 8 y 9). Las ilustraciones han sido seleccionadas porque mantienen una relación directa con la situación descrita por las canciones, pero desde una perspectiva crítica. Por ejemplo, en «Picky picky» se pone de manifiesto el acoso sexual en las discotecas y la mercantilización, cosificación e hipersexualización de la mujer como reclamo publicitario (ANEXO 9). El procedimiento para llevar a cabo el debate es el mismo que en las actividades anteriores. Ya inmersos en el tema, es el momento perfecto para que los estudiantes se cuestionen sobre la definición de feminismo, su antónimo y conceptos relacionados como sexo débil o instinto paternal ${ }^{14}$. Para ello, se hace uso del DRAE y se aprovecha para debatir sobre las recientes polémicas relacionadas con esta institución cultural y por qué ha sido tachada de sexista ${ }^{15}$.

Si nos centramos en un aspecto más cultural, los estudiantes pueden explicar a sus compañeros qué mujeres son consideradas de gran importancia en su país o a cuáles admiran. El profesor, por su parte, puede dar a conocer a algunas figuras femeninas de gran importancia en España como María Moliner, la cual no pudo entrar en la RAE porque no se admitían mujeres en su época, o Clara Campoamor, una de las principales propulsoras del sufragio femenino en España.

13 Moderna de Pueblo es el nombre artístico de la ilustradora Raquel Corcolés (1986, Reus), quien creó un blog bajo ese mismo nombre en 2010 para dar a conocer sus viñetas humorísticas e irónicas. Resulta interesante el camino que ha tomado esta artista en cuanto al enfoque del feminismo. Destaca su libro Idiotizadas: Un cuento de empoderhadas (2017) y su autocrítica «Mis viñetas más machistas» 01/12/2017 publicada en su página web (Modernadepueblo.com). En cuanto a Feminista Ilustrada, es el nombre de la página creada en 2015 por Maria Murnau y Helen Sotillo. Murnau (Cádiz, 1991) estudió comunicación audiovisual y decidió difundir sus campañas sobre igualdad de género a través de ilustraciones.

${ }^{14}$ Cabe destacar que el Plan Curricular del Instituto Cervantes (PCIC) no contempla el uso de ciertas palabras como patriarcado o matriarcado hasta un nivel C2 en el apartado 4.1. Relaciones familiares [ $\underline{\underline{ }}$. Nociones especificas 3.1.8.]. Sin embargo, debido a su similitud con la palabra anglosajona, no supondría un inconveniente trabajar con ella en clase.

15 «La RAE se niega a eliminar la polémica acepción de "mujer fácil”». $A B C$, (26/01/2018). Recuperado el 05/05/2018 de: http://www.abc.es/cultura/abci-mujer-facil-rae-201801261002 noticia.html 


\subsection{Actividad 4 (superación): «Haz tu versión»}

Como tarea final a las actividades musicales se ofrece una alternativa feminista a la canción «Picky picky» disponible en Youtube $^{16}$ y se propone a los estudiantes que escriban una versión del estribillo de «Propuesta indecente», al tener en cuenta que el ritmo pausado y lento de la bachata facilita la realización de la actividad. Para ello, se les sugiere que mantengan la estructura principal del estribillo y que cambien las palabras o expresiones que consideren ofensivas. Por ejemplo «Y si te invito a una copa...», puede ser neutralizada por «Y si nos vamos de copas...» (Véase el ANEXO 12 con un ejemplo realizado por los estudiantes).

\subsection{Actividad 5 (re-acción): «Un poco de humor»}

Se presentan diversas imágenes en las que se observan situaciones machistas o que invitan a pensar que lo $\operatorname{son}^{17}$, como es el caso de una pareja en la que el hombre paga la cuenta (ANEXO 10).

Para trabajar la inteligencia visual y lingüística, se les propone a los estudiantes modificar las imágenes mediante el humor, dado que es un aspecto propio de la idiosincrasia hispana. Además, como señalan Mendiburo y Páez (2011: 91), el humor desde el aspecto intrapersonal es una forma de afrontamiento que «permite disminuir emociones negativas y mantener visiones positivas y realistas de situaciones adversas». Previamente, se muestra un ejemplo como referencia en el que inspirarse (ANEXO 11).

\subsection{EI WhatsApp: «La aventura continúa»}

Esta herramienta funciona como el marco que engloba y recoge el trabajo realizado por los estudiantes durante toda la secuencia de actividades; además, sirve para generar un aula viva en la que el alumnado gana autonomía y, al mismo tiempo, se cohesiona el grupo al intercambiar opiniones en un ambiente no estrictamente académico. Se fomenta la autocorrección -tanto escrita como oral-, y la independencia, ya que el profesor solo interviene dentro del aula para hacer las correcciones pertinentes.

En primer lugar, en la actividad Haz tu versión, los estudiantes deben practicar la pronunciación mandando un audio con el estribillo compuesto por ellos mismos. En $U n$ poco de humor, se les anima a que busquen imágenes de su entorno en las que se represente una situación de desigualdad. Como idea, se les sugiere que busquen fotografías de su país sobre la denominada «tasa rosa» ${ }^{18}$.

Por último, mediante la infografía titulada «Algunas cosas para las que sirve el feminismo» (ANEXO 13), se permite trabajar de forma práctica y no extensa la función de finalidad del subjuntivo. Ejemplo: «El feminismo sirve para que los padres puedan pasar más tiempo con sus bebés recién nacidos».

\footnotetext{
${ }^{16}$ Buscar «Picky picky feminista». La letra que se visualiza fue escrita por dos jóvenes argentinas, por lo que puede promoverse el aprendizaje del acento y léxico americano, así como también el uso del voseo.

${ }^{17}$ En este sentido, se trabaja el neologismo «micromachismos» que «hacen referencia a actitudes sexistas encubiertas y culturalmente aceptadas», como dice el artículo «Micromachismos: 4 muestras sutiles de machismo cotidiano» de Regader, B. (psicologiaymente.net).

${ }^{18}$ Como señala la FACUA «La conocida como tasa rosa representa un incremento de precio abusivo en una serie de artículos destinados artificialmente a las consumidoras cuando sus características técnicas no difieren de sus versiones genéricas.»
} 


\section{Evaluación}

Debido a las características excepcionales de esta secuencia didáctica, no resultaría provechoso evaluar el contenido aprendido mediante un control, prueba o examen. En su lugar, se ha optado por la elaboración de una rúbrica como método de autoevaluación que permita al alumnado tomar conciencia sobre su propio aprendizaje, ya que como apunta el capítulo 9 del MCER «el potencial más importante de la autoevaluación está en su utilización como herramienta para la motivación y para la toma de conciencia» (Consejo de Europa 2002: 188).

\begin{tabular}{|c|c|c|c|c|c|}
\hline \multicolumn{2}{|r|}{ Criterios de Evaluación (1- Siempre 2- Casi siempre 3- En ocasiones 4- Nunca) } & 1 & 2 & 3 & 4 \\
\hline A. & $\begin{array}{l}\text { He tomado conciencia sobre las ideas preconcebidas que asocio con el hombre y } \\
\text { la mujer. }\end{array}$ & & & & \\
\hline B. & He reflexionado sobre el contenido de las canciones trabajadas en clase. & & & & \\
\hline C. & $\begin{array}{l}\text { He entendido la diferencia entre los conceptos de: machismo, feminismo, } \\
\text { hembrismo, misoginia, misandria, micromachismo y androcentrismo. }\end{array}$ & & & & \\
\hline D. & $\begin{array}{l}\text { He sido capaz de dar un enfoque igualitario o neutralizar la letra de una canción } \\
\text { degradante. }\end{array}$ & & & & \\
\hline E. & Mi trabajo no se ha limitado únicamente a las horas de clase. & & & & \\
\hline F. & He roto mi discurso etnocentrista escuchando a mis compañeros/as. & & & & \\
\hline G. & $\begin{array}{l}\text { En la clase, ha habido un ambiente distendido en el que he podido expresar } \\
\text { libremente mi opinión. }\end{array}$ & & & & \\
\hline H. & He encontrado estimulante el método de trabajo. & & & & \\
\hline
\end{tabular}

Tabla 2. Muestra de autoevaluación

\section{Obstáculos}

Una dificultad a tener en cuenta es la posible falta de confianza entre el profesor y el grupo o la falta de complicidad entre los propios miembros de la clase.

Por otro lado, en el caso de que estas actividades quieran llevarse a cabo en un grupo con estudiantes residentes (universitarios o empleados), hay que tener en cuenta la posible falta de tiempo para participar y realizar las actividades vía WhatsApp en el tiempo establecido. El uso de esta aplicación puede no ser recomendable con estudiantes menores, debido a la necesidad de dar su número de teléfono personal. En ese caso, o en cualquier otro en el que suponga un inconveniente, se recomienda el uso de aplicaciones similares como Telegram, ya que no es necesario dar datos privados.

\section{Conclusiones}

La estimulación a través de diferentes materiales aporta una perspectiva cognitiva diferente, ya que se han usado herramientas y materiales de diversa índole -música, imágenes, infografía y aplicación de mensajería instantánea- y se ha estimulado el aprendizaje a través de las IIMM.

Tratar un tema de actualidad permite que los estudiantes debatan usando de forma conjunta todos los contenidos gramaticales propios de su nivel al tiempo que ponen en práctica el léxico relacionado con el tema y refuerzan la conciencia intercultual.

Gracias a la metodología, los materiales y las herramientas empleadas, se ha permitido trabajar la Interculturalidad de manera alternativa ya que las actividades no se han 
limitado a hacer la previsible y prototípica pregunta de las clases de idiomas sobre cómo es algún hábito o costumbre en el país de los estudiantes.

Por último, pero no por ello menos importante, no se puede ignorar la importancia del profesor como moderador y guía en el debate, al tratarse de un tema que puede generar opiniones controvertidas y enfrentadas en la clase.

\section{Bibliografía}

ABC (26/01/2018). «La RAE se niega a eliminar la polémica acepción de "mujer fácil"» Recuperado el 06/05/18, de: http://www.abc.es/cultura/abci-mujer-facil-rae201801261002_noticia.html

Battagliero Bocco, F., Fontana Oltra, J.V., Navarro Morales, M. (2017): «El vídeo, el cómic y el rap: una forma diferente de desbloquear al candidato de DELE» Foro E/LE, 13, 23-33. DOI:10.7203/foroele.13.10841

Centro Nacional de Investigación e InNOVAción Educativa (CNIIE) (2015). La enseñanza de temas controvertidos. Secretaría General Técnica. Centro de Publicaciones. Ministerio de Educación, Cultura y Deporte. Recuperado el 06/05/18 de: https://sede.educacion.gob.es/publiventa/d/20648/19/1

Clarke, P. (2000): «Teaching controversial issues». Green, Teacher, 62, 29-32.

CONSEJO DE EuROPA (2002). Marco común europeo de referencia para las lenguas: aprendizaje, enseñanza, evaluación. Madrid: Anaya.

CórCOLES, R. (2010). «Moderna de pueblo». Recuperado el 06/05/2018, de: http://modernadepueblo.com/

Coronado, L., GarcíA, J. (1990): «De cómo usar canciones en el aula». II Congreso Nacional de la ASELE. Español para Extranjeros: Didáctica e Investigación. Recuperado el 06/05/18, de: http://cvc.cervantes.es/ensenanza/biblioteca_ele/asele/asele_ii.htm

FEDERACIÓN DE ASOCIACIONES DE CONSUMIDORES y USUARIOS DE ANDALUCÍA (2018): «Maquinillas de afeitar "para mujeres": idénticas al resto pero hasta un $171 \%$ más caras, denuncia FACUA», FACUA. Recuperado el 20/07/2018 de: https://www.facua.org/es/noticia.php?Id=12552

FERnÁndez Poncela, A. (2010): «Relaciones de pareja: paremias, introyectos y discursos.» Géneros. Revista de investigación y divulgación sobre los estudios de género, 17, 97-119

Gardner, H. (1993) La Mente No Escolarizada. Cómo piensan los niños y cómo deberían enseñar las escuelas. Barcelona: Ediciones Paidós.

Gómez UrZaiz, B. (2012) «¿Feminista, yo? No, gracias» (05/12/2012), El País. Recuperado el 06/05/18 de: https://smoda.elpais.com/moda/feminista-yo-no-gracias/

Instituto CeRvantes (2006): Plan Curricular del Instituto Cervantes (PCIC). Madrid: Biblioteca Nueva. 
Jakubowski, K., Finkel, S., Stewart, L., Müllensiefen, D. (2017): «Dissecting an Earworm: Melodic Features and Song Popularity Predict». Psychology of Aesthetics, 2, $122-135$

LlOPIS GARCÍA, R. (27/10/15) «Entrevista a Reyes Llopis García, experta en gramática cognitiva ELE». Difusión. Recuperado el 06/05/2018, de: https://www.difusion.com/entrevista-a-reyes-llopis-garcia-experta-en-gramaticacognitiva-y-ele/

Mendiburo, A., PÁEz, D. (2011). «Humor y cultura: correlaciones entre estilos de humor y dimensiones culturales en 14 países». Boletín de psicología, 102, 89-105.

Munau, M., Sotillo, H. (2015). «Feminista ilustrada». Recuperado el 06/05/2018 de: https://feministailustrada.com/

Petrelli, J., Berella, L. (13/01/17). «Picky picky feminista» [Archivo de video] Recuperado el 06/05/18, de: https://www.youtube.com/watch?v=fVJy56N-iWw

REGADER, B. (2017). «Micromachismos: 4 muestras sutiles de machismo cotidiano». Psicologiaymente.net. Recuperado el 06/05/2018, de: https://psicologiaymente.net/social/micromachismos

SÁNCHEZ JÓDAR, J.A., DOMENE BENITO, R. (2017): «Cuando un príncipe besa a una rana: ¡Sorpresa! Una propuesta didáctica desde la homosexualidad». Foro E/LE, 13, 189-203. DOI: 10.7203 /foroele. 13.10850 


\section{(7) INDICATIVO}

PRESENTE: Te digo lo que pienso y me dices.

P. PERFECTO: ¿Has pensado en lo que te he dicho?

P. INDEFINIDO: Steven se fue y no pude terminar de rebatir.

P. IMPERFECTO: El tema era muy interesante y lo explicaba muy bien.

P. PLUSCUAMPERFECTO: Pues nunca había pensado en eso.

FUTURO: Poco a poco lo tendremos más claro.

FUTURO P.: Lo habrá entendido mal.

CONDICIONAL: Me gustaría participar en el debate.

CONDICIONAL C.: No le habría insistido bajo ningún concepto.

SUBJUNTIVO

PRESENTE: Quizás encontremos un punto en común.

P.PERFECTO: Espero que no me hayas malinterpretado.

P.IMPERFECTO: No sabía que defendieses/defendieras esas posturas.

* P.PLUSCUAMPERFECTO: Me hubiese gustado escucharos a todos.

\section{IMPERATIVO}

AFIRMATIVO: Respetaos los unos a los otros, por favor.

NEGATIVO: No te enfades por tonterías.

GERUNDIO: $\quad$ Escuchándote me he dado cuenta de que...

\section{ESTRUCTURAS CONDICIONALES}

I. $\mathrm{Si}+$ presente de indicativo / presente, futuro, imperativo.

II. Si + imperfecto de subjuntivo / condicional simple o condicional compuesto

III. Si + pluscuamperfecto de subjuntivo / condicional compuesto o plusc. de subjuntivo

\section{ESTILO INDIRECTO}

Ha dicho que $+(\mathbf{\Delta}$

Dijo que +(

\begin{tabular}{|c|c|c|}
\hline \multicolumn{3}{|c|}{ CONCORDANCIA INDICATIVO-SUBJUNTIVO ¿CÓMO LOS COMBINO? } \\
\hline DESEOS & - Ojalá $+\infty$ & - No esperaba que + \\
\hline SENTIMIENTOS & - Me molesta que + & $-\mathrm{Me} \xi$ \\
\hline OPINIÓN & - No pienso que $+\boldsymbol{\Delta}$ & - No creía que $+\square$ \\
\hline HIPÓTESIS & - Es probable que+ & - Puede que $+\infty$ \\
\hline
\end{tabular}

RECURSOS PARA DEBATIR: ESTRUCTURAS Y CONECTORES

\section{EXPRESAR OPINIÓN}

-Creo que este tema está a la orden del día

-Supongo que habrá maneras de que salga bien

\begin{tabular}{ll}
\hline AÑNDIR INFORMACIÓN & \\
\hline -Yo también diría que & - Además - También/tampoco -Luego \\
-No olvidemos que & - Es necesario - Asimismo -Igualmente
\end{tabular}

INTERRUMPIR

- Bueno, pero yo - -Perdona que te corte $\quad$ - Te interrumpo un momento porque

- Puede que tengas razón, sin embargo

ATRAER LA ATENCIÓN

- ¿Te has fijado en...?

-Eso me recuerda que
- Imagínate que -Mira -Escúchame un segundo

FINAL DE FRASE: - ¿Sabes? - ¿No? -¿Verdad? - ¿Me entiendes?

Anexo 1. Guía de conversación del estudiante 
CONCEPTOS: (1) Igualdad/desigualdad, (2) estereotipo/cliché/tópico/prejuicio, (3) canon de belleza, (4) baja por/de matemidad/paternidad, (5) instinto maternal/paternal, (6) sexo débil y fuerte, (7) ser fácil, (8) ser una estrecha, (9) acosar, (10), ser un baboso/a, (11) feminismo, (12) machismo, (13) hembrismo, (14) misandría, (15) discurso androcéntrico (micromachismo)

\section{Act. $1 \mathrm{Di}$ lo primero que piensas.}

Desde tu experiencia, ¿puedes explicar por qué has escrito estas

Vocabulario

palabras? Di un ejemplo. ¿Coincides con tus compañeros/as?

¿Crees que .......... podría estar en $\delta$, o y/o $Q$ ?

¿Crees que $\hat{\delta}$, ㅇ y a de todo el mundo responden a las palabras

seleccionadas?

Act. 2 ¿Escuchas lo que cantas?

¿Podrías describir la situación de la canción?

Vocabulario

¿Cuál te parece que es la imagen que se refleja de $\delta$ y

¿Alguna vez te has sentido identificado/a con una situación similar? ¿Y en

(6), (7), (8), (9),

tu entorno?

(10)

Act. 3 ¿Qué hay detrás de las canciones?

¿Crees que estas viñetas reflejan una situación de desigualdad? ¿Por

Vocabulario

qué?

(11), (12), (13),

¿Cuál es la intención de las viñetas?

(14), (15)

¿Crees que un hombre puede ser feminista y una mujer machista?

¿Cuál es el antónimo de feminismo?

Anexo 2. Guía del profesor 


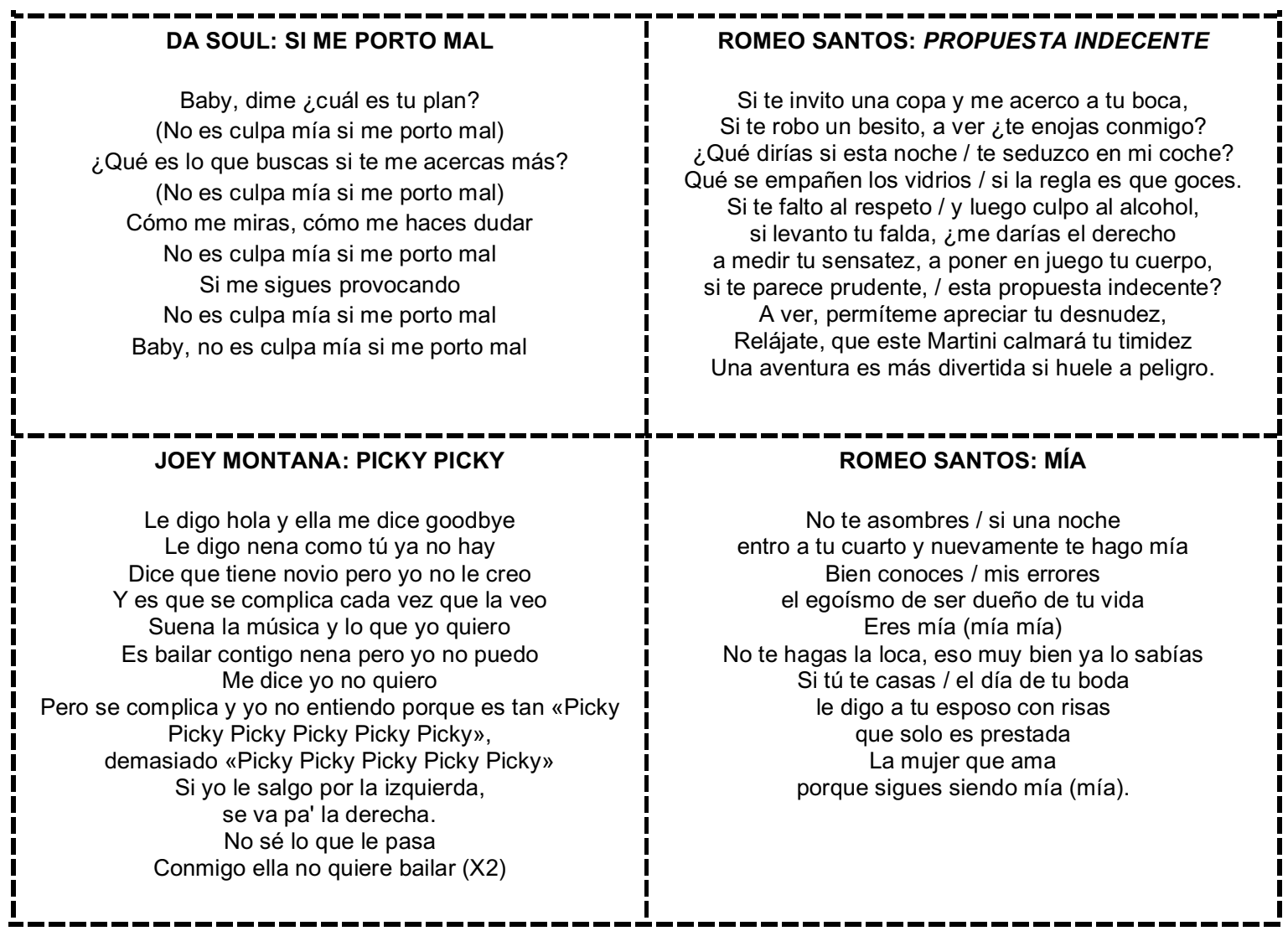

Anexo 3. Fragmentos de las canciones

Baby, dime ¿cuál es tu plan? (No es culpa mía si me porto mal) ¿Qué es lo que si te me acercas más?

(No es culpa mía si me porto mal) Cómo me , cómo me haces dudar

No es culpa mía si me porto mal me sigues provocando

No es culpa mía si me porto mal Baby, no es culpa mía si me porto mal
Baby, dime ¿cuál es tu plan?

(No es culpa mía si me porto ¿Qué es lo que buscas si te me acercas más?

(No es culpa mía si me porto mal)

Cómo me miras, cómo me haces es culpa mía si me porto mal Si me sigues provocando

No es culpa mía si me porto mal Baby, no es culpa mía si me porto mal
Quiero una mujer bien no me diga naa

que cuando me vaya a la callada que en la mañana no diga naa'

que aunque no le guste, que tome y se quede callada y no diga naa'

Quiero una mujer que no diga naa'

Ya no hables más y dame un

Llego la del beso

Llevamos como diez horas hablando y tú que bla bla blaaa
Quiero una bien bonita, callada

que no me diga naa'

que cuando me vaya a la noche y vuelva en la

$$
\text { no diga naa' }
$$

que aunque no le guste, que tome y se quede callada y no diga na'

Quiero una mujer que no diga naa'

Ya no más y dame un beso

Llego la hora del beso

Llevamos como horas hablando y tú 
Le digo y ella me dice goodbye Le digo nena como tú ya no hay Dice que tiene novio pero yo no le creo Y es que se complica cada vez que la veo Suena la y lo que yo quiero

Es bailar contigo nena pero yo no puedo Me dice yo no

Pero se complica y yo no entiendo porque es tan «Picky Picky Picky Picky Picky Picky», demasiado «Picky Picky Picky Picky Picky»"

Si yo le salgo por la se va pa' la derecha. No sé lo que le pasa

Conmigo no quiere bailar (X2)
Le digo hola y ella me dice goodbye Le digo nena como tú ya no hay Dice que tiene pero yo no le creo

$Y$ es que se complica cada vez que la

Suena la música y lo que yo quiero Es bailar contigo nena pero yo no puedo Me dice no quiero

Pero se complica y yo no entiendo porque es tan «Picky Picky Picky Picky Picky Picky»,

demasiado «Picky Picky Picky Picky Picky»

Si yo le salgo por la izquierda, se va pa' la No sé lo que le pasa

Conmigo ella no quiere (X2)

Anexo 4. Fragmentos de las canciones con espacios (rellenahuecos) 


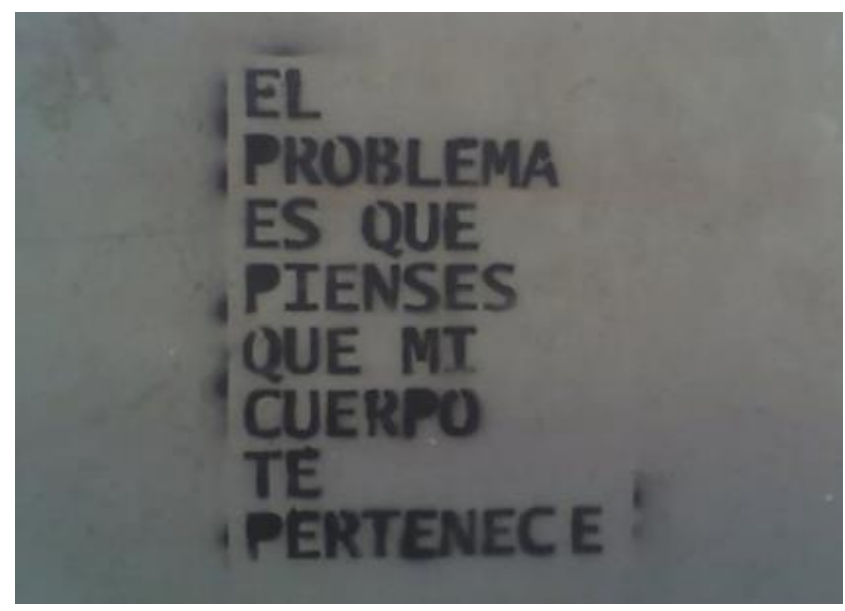

Anexo 5. Imagen para «Eres mía»

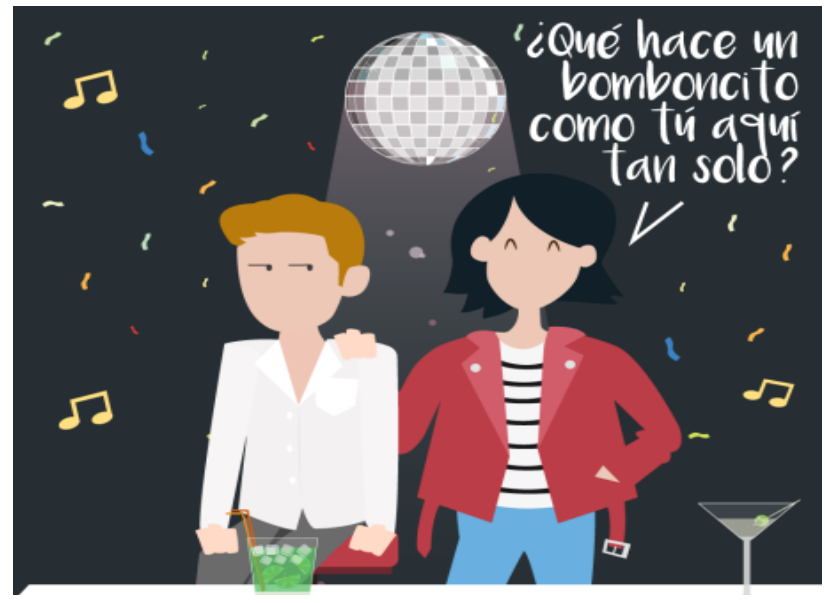

Anexo 7. Imagen para «Picky picky»

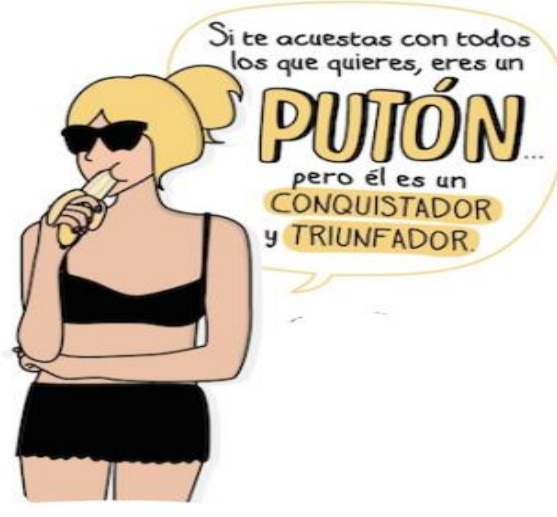

Anexo 6. Imagen para "Propuesta indecente»

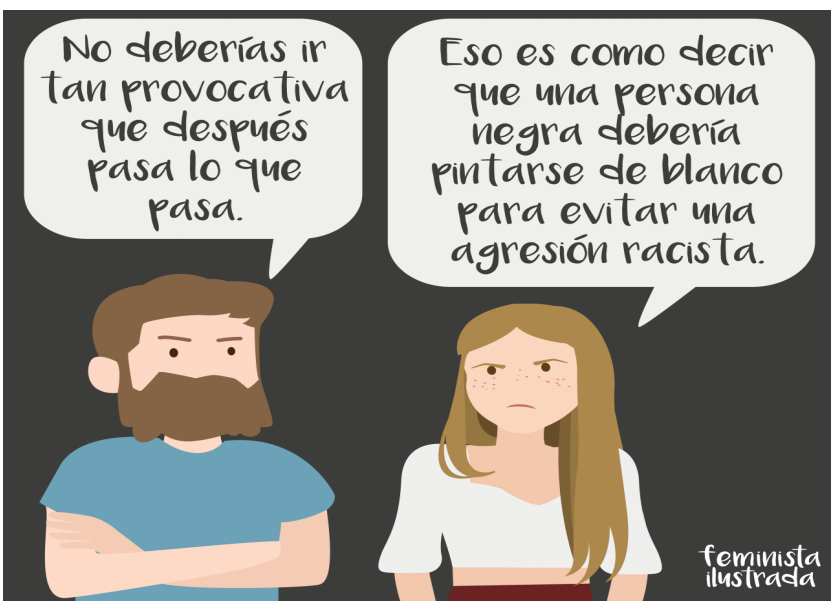

Anexo 8. Imagen para «Si me porto mal»

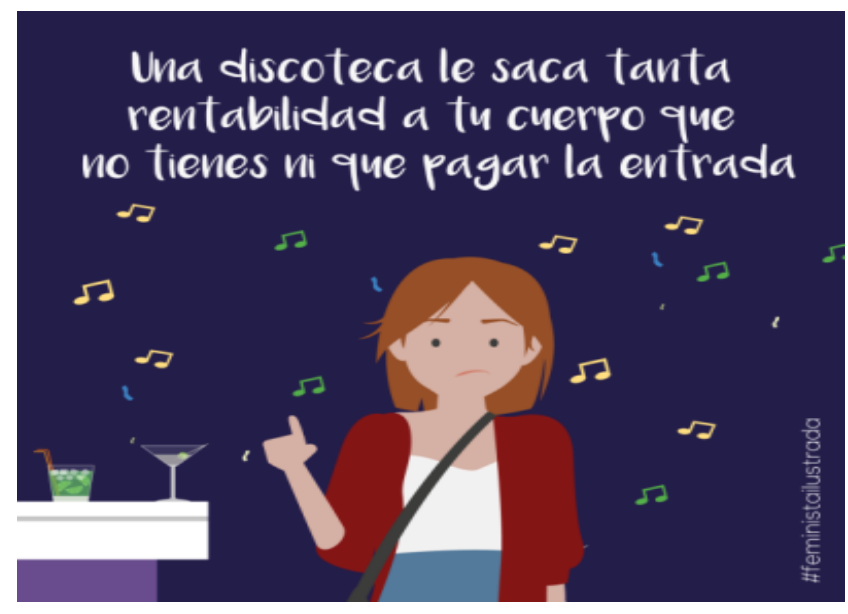

Anexo 9. Imagen para "Picky picky» 

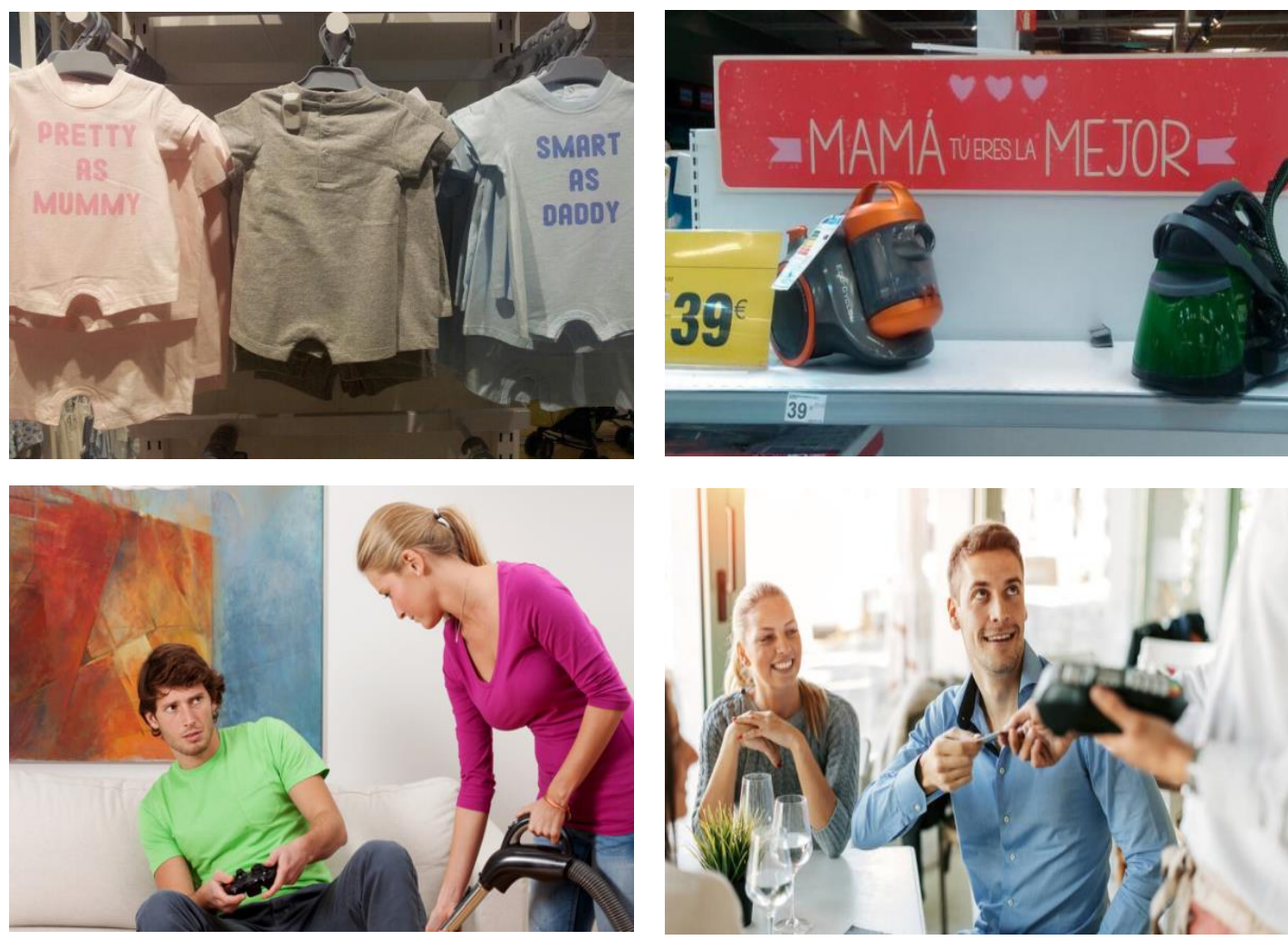

Anexo 10. Imágenes para «Un poco de humor»

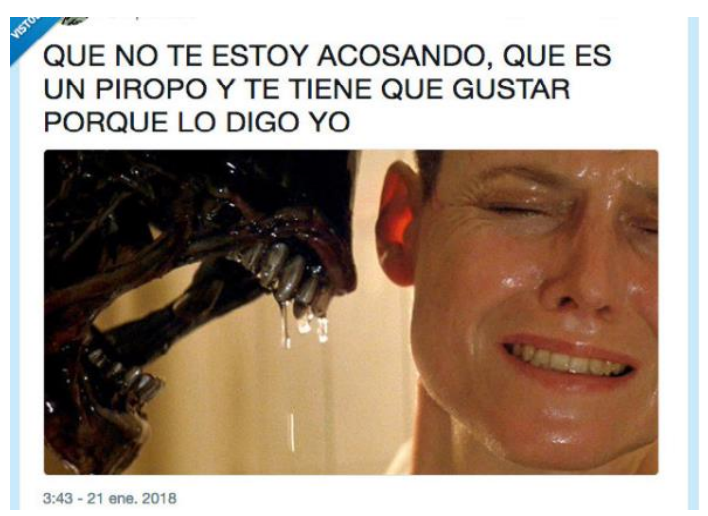

Anexo 11. Ejemplo de imagen para «Un poco de humor»

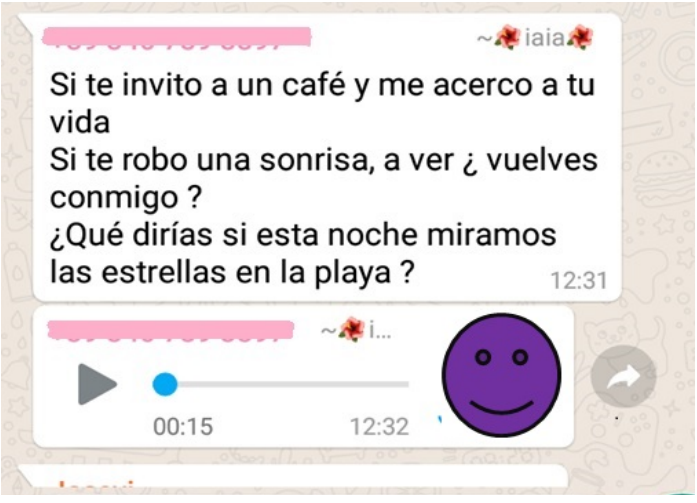

Anexo 12. Ejemplo de los estudiantes 


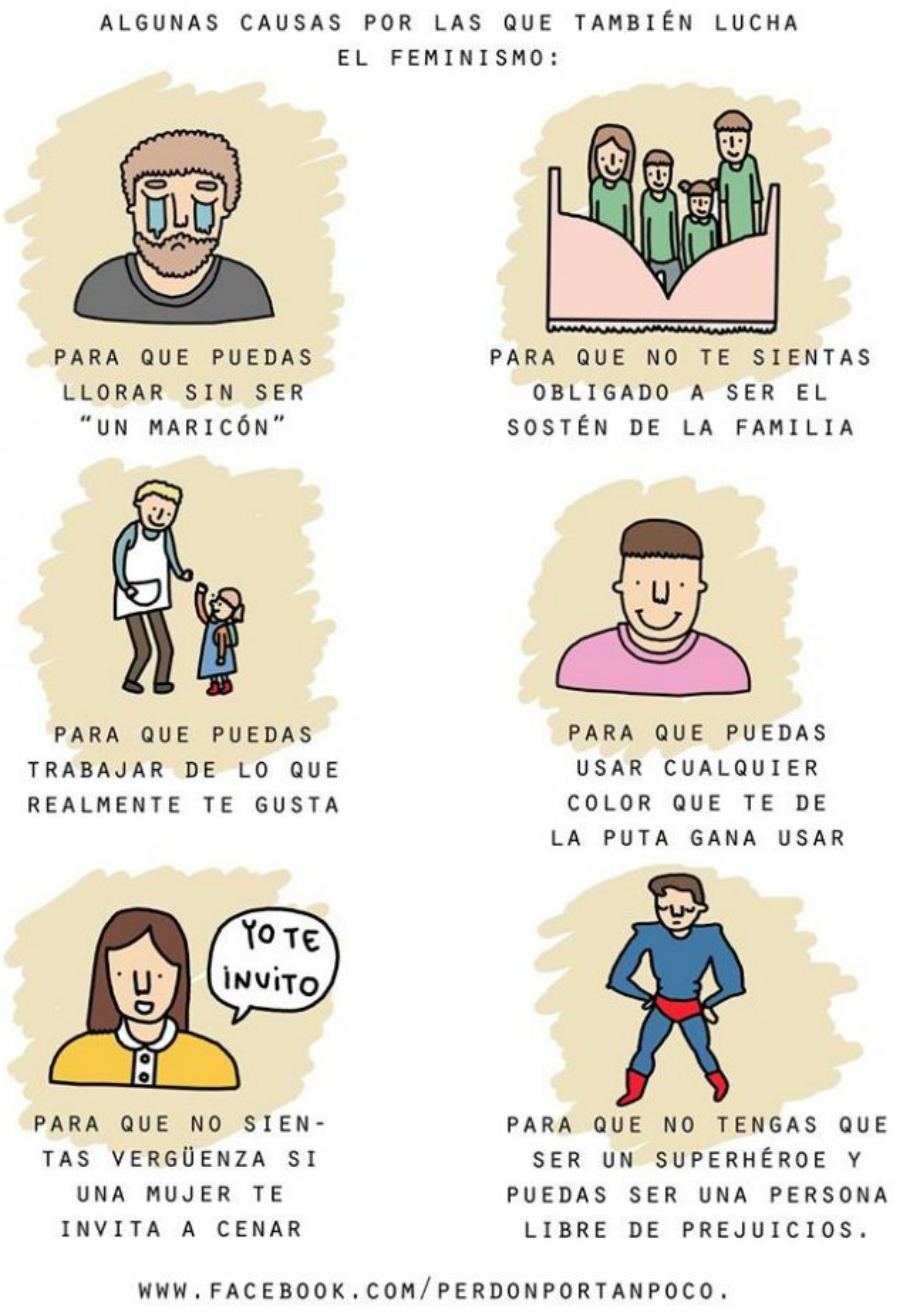

Anexo 13. Infografia para actividad «Para que + subjuntivo» 